\title{
OS DESAFIOS DA DOCÊNCIA NO ENSINO SUPERIOR FRENTE A INCLUSÃO DE PESSOAS COM DEFICIÊNCIA NAS UNIVERSIDADES
}

\section{LOS DESAFÍOS DE LA EDUCACIÓN SUPERIOR EN EDUCACIÓN SUPERIOR CON LA INCLUSIÓN DE PERSONAS CON DISCAPACIDAD EN LAS UNIVERSIDADES}

\author{
THE CHALLENGES OF HIGHER EDUCATION IN HIGHER EDUCATION WITH \\ THE INCLUSION OF DISABLED PEOPLE IN UNIVERSITIES
}

\author{
Katiuscia C. Vargas ANTUNES ${ }^{1}$ \\ Cassiano Caon AMORIM ${ }^{2}$
}

RESUMO: Tratar da inclusão educacional de pessoas com deficiência (PCD) não é propriamente um tema novo no cenário brasileiro. Tomando a Constituição Federal de 1988 como marco legal e histórico, é possível afirmar que, há pelo menos 30 anos, a temática da inclusão educacional vem ganhando relevo no campo das políticas educacionais, da investigação em educação e das práticas docentes. Por outro lado, quando tratamos da inclusão no ensino superior nos deparamos com uma situação contrária. Tanto as políticas públicas quanto a produção de conhecimento são muito recentes, o que configura a inclusão de PCD no ensino superior ainda um campo aberto, com muitas frentes de pesquisa, nas diferentes áreas do conhecimento. Um dos temas de investigação que se impõem é a docência no ensino superior e os desafios que os professores enfrentam frente à inclusão de PCD nas universidades. Considerando o tema exposto, o artigo tem como objetivo fazer uma reflexão sobre o quanto o acesso de estudantes com deficiência no ensino superior, em especial a partir da política de reserva de vagas (Lei 13.409/2016), tem impactado no cotidiano das salas de aula, em particular nas práticas docentes. Realizamos uma revisão de literatura, a partir de uma pesquisa na base de dados do Scielo (Scientific Electronic Library Online), entre 2008 e 2018, buscando por artigos sobre a docência no ensino superior e a inclusão de PCD. Os textos foram quantificados e analisados qualitativamente, buscando identificar os desafios encontrados no contexto da docência no ensino superior frente à inclusão. A complexidade envolvida no processo de inclusão de PCD no ensino superior é grande, em especial no que toca à atuação do docente. Os artigos nos sinalizam diferentes desafios à prática docente que vão desde a sua postura diante de estudantes com deficiência até a sua capacidade de ressignificar e modificar a sua prática tendo a inclusão como um princípio pedagógico.

PALAVRAS-CHAVE: Ensino superior. Inclusão educacional. Docência.

1 Universidade Federal de Juiz de Fora (UFJF), Juiz de Fora - MG - Brasil. Professora Adjunta do Departamento de Educação. Professora dos Programa de Pós-Graduação em Políticas Públicas e Avaliação da Educação Pública (PPGP/CAED/UFJF). ORCID: https://orcid.org/0000-0003-2861-551X. E-mail: katiuscia.vargas@educacao.ufjf.br

${ }^{2}$ Universidade Federal de Juiz de Fora (UFJF), Juiz de Fora - MG - Brasil. Professor Associado do Departamento de Educação. Professor do Programa de Pós-Graduação em Políticas Públicas e Avaliação da Educação Pública (PPGP/CAED/UFJF) e do Programa de Pós-graduação em Educação (PPGE/FACED/UFJF). ORCID: https://orcid.org/0000-0003-3326-8524. E-mail: cassianoamorim@hotmail.com 
RESUMEN: Abordar la inclusión educativa de las personas con discapacidad (PCD) no es exactamente un tema nuevo en el escenario brasileño. Tomando la Constitución Federal de 1988 como un hito legal e histórico, se puede decir que durante al menos 30 años el tema de la inclusión educativa ha ido ganando importancia en el campo de las políticas educativas, la investigación en educación ensino las prácticas de enseñanza. Por otro lado, cuando tratamos con la inclusión en la educación superior, nos enfrentamos a una situación contraria. Tanto las políticas públicas como la producción de conocimiento son muy recientes, lo que configura la inclusión de PCD en la educación superior, que sigue siendo un campo abierto, con muchos frentes de investigación, en diferentes áreas de conocimiento. Uno de los temas de investigación más importantes es la enseñanza en educación superior ensino los desafios que enfrentan los docentes frente a la inclusión de PCD en las universidades. Teniendo en cuenta el tema anterior, el articulo pretende reflexionar sobre el impacto que ha tenido en la vida diaria de los estudiantes con discapacidades en la educación superior, especialmente a partir de la politica de reservar lugares (Ley 13.409 / 2016). Particularmente en las prácticas de enseñanza. Llevaremos a cabo una revisión bibliográfica sistemática, basada en una búsqueda en la base de datos Scielo (Scientific Electronic Library Online), entre 2008 ensino 2018, en busca de artículos sobre enseñanza de educación superior ensino la inclusión de PCD. Los textos se cuantificarán ensino se analizarán cualitativamente, buscando identificar los desafios encontrados en el contexto de la enseñanza en la Educación Superior que enfrenta la inclusión.

PALABRAS CLAVE: Enseñanza superior. Inclusión educativa. Enseñanza.

ABSTRACT: Talk about the educational inclusion of people with disabilities (PCD) is not exactly a new theme in the Brazilian scenario. Taking the 1988 Federal Constitution as a legal and historical landmark, it can be said that for at least 30 years the issue of educational inclusion has been gaining prominence in the field of educational policies, research in education and teaching practices. On the other hand, when we deal with inclusion in Higher Education we face a contrary situation. Both public policies and knowledge production are very recent, which configures the inclusion of PCD in Higher Education still an open field, with many research fronts, in different areas of knowledge. One of the most important research themes is teaching in higher education and the challenges teachers face facing the inclusion of PCD in universities. Considering the above theme, the article aims to reflect on how much the access of students with disabilities in Higher Education, especially from the policy of reserving vacancies (Law 13.409 / 2016), has impacted the daily life of the classrooms. particularly in teaching practices. We will conduct a systematic literature review, based on a search in the Scielo database (Scientific Electronic Library Online), between 2008 and 2018, searching for articles on higher education teaching and the inclusion of PCD. The texts will be quantified and qualitatively analyzed, seeking to identify the challenges found in the context of teaching in Higher Education facing inclusion.

KEYWORDS: Higher education. Educational inclusion. Teaching.

O exercício da docência nunca é estático e permanente; é sempre processo, é mudança, é movimento, é arte; são novas caras, novas experiências, novo contexto, novo tempo, novo lugar, novas informações, novos sentimentos, novas interações (CUNHA, 2004, p. 530).

RIAEE - Revista Ibero-Americana de Estudos em Educação, Araraquara, v. 15, n. esp. 2, p. 1465-1481, ago. 2020. e-ISSN: $1982-5587$. 


\section{Introdução}

Considerando a recente discussão sobre a inclusão e pessoas com deficiência (PCD) no ensino superior e as muitas possibilidades de investigação que estão postas, neste texto, o objetivo é fazer uma reflexão sobre o quanto o acesso de estudantes com deficiência no ensino superior, em especial a partir da política de reserva de vagas (Lei 13.409/2016), tem impactado no cotidiano das salas de aula, em particular nas práticas docentes. Em uma revisão de literatura, a partir da base de dados do Scielo (Scientific Electronic Library Online), foram selecionados artigos sobre a docência no ensino superior e a inclusão de PCD, entre os anos de 2008 e 2018, elegendo como marco temporal para a pesquisa a promulgação da Política Nacional de Educação Especial na perspectiva da Educação Inclusiva em 2008. Os artigos encontrados nos ajudaram a compreender o cenário sobre a inclusão de PCD no ensino superior, tendo como recorte a docência neste segmento de ensino ${ }^{3}$.

Buscaremos explicitar, ao longo deste artigo, aspectos relacionados à inclusão educacional de estudantes com deficiência no ensino superior, tendo como recorte a docência e os impactos que a presença desses estudantes trazem para o trabalho docente. Na primeira seção apresentaremos o conceito de inclusão que respalda a discussão da temática, apontando a inclusão educacional não somente como uma política, mas sobretudo como um princípio pedagógico. Em seguida, faremos uma discussão sobre a docência no ensino superior frente a democratização do acesso de PCD, sobretudo a partir da Lei 13.409/2016. Na terceira e quarta seções apresentaremos a metodologia e os dados encontrados durante o processo de pesquisa, buscando conhecer e compreender o que estudiosos de diferentes áreas do conhecimento vem apontando sobre a docência no ensino superior na relação com a inclusão educacional de estudantes com deficiência na universidade. Por fim, teceremos algumas considerações sobre as possibilidades e os desafios que se colocam para o exercício da docência e a promoção da inclusão com qualidade de pessoas com deficiência no ensino superior.

\section{Inclusão educacional como um princípio pedagógico: da ruptura com padrões de excelência no ensino baseados em critérios de homogeneidade}

Apontar a inclusão como um princípio pedagógico implica em retomar alguns aspectos que caracterizam a universidade como espaço de produção e troca de conhecimentos, além de ser um espaço que possibilita o convívio social. A universidade tem como função

\footnotetext{
${ }^{3}$ Os dados referentes aos artigos selecionados serão apresentados na seção três deste artigo.
} 
social a produção de conhecimento com vistas a promover o desenvolvimento da cultura, da ciência, da tecnologia e, por conseguinte, do próprio ser humano (DEMO, 1997). Espaços como os da universidade precisam oportunizar e incentivar uma educação democrática, que tenha como princípio o reconhecimento das diferenças.

Nesse contexto, um grande desafio que se coloca para essas instituições é implementar políticas e práticas que promovam a inclusão de pessoas com deficiência, rompendo com uma cultura seletiva e excludente que, de alguma maneira, marca o ensino superior. Para as pessoas com deficiência, o ensino superior era algo inatingível, considerando os critérios de seleção que historicamente marcaram o acesso à universidade. Além disso, a cultura universitária foi e, em alguma medida ainda é, marcada por padrões de excelência que pressupõem que apenas os "mais capazes", ou melhor, aqueles que se adaptam a essa cultura, alcancem êxito nos estudos.

Se considerarmos a diversidade que habita os espaços universitários, tanto no que se refere a questões culturais, raciais, étnicas, religiosas, de gênero e das condições relacionadas à deficiência, temos que colocar em xeque tais padrões, promovendo uma revisão dos critérios de excelência e qualidade que a universidade prima e que sempre foram pautados por valores de exclusão, homogeneidade e individualismo. Numa proposta inclusiva, diante de uma sociedade cada vez mais intercultural e heterogênea, a excelência da universidade talvez passe a ser pautada por princípios como cooperação, negociação, inclusão e coletividade (RODRIGUES, 2012).

A posição que se assume a partir da cultura inclusiva é a de que se deve rejeitar no contexto universitário qualquer forma e exclusão.

O conceito de Inclusão no âmbito específico da Educa ão, implica, antes de mais, rejeitar, por princípio, a exclusão (presencial ou académica) de qualquer aluno da comunidade escolar. Para isso, a escola que pretende seguir uma política de Educação Inclusiva (EI) desenvolve políticas, culturas e práticas que valorizam o contributo activo de cada aluno para a constru o de um conhecimento construído e partilhado e desta forma atingir a qualidade académica e sócio cultural sem discriminação (RODRIGUES, 2006, p. 2, grifo nosso).

Para Rodrigues (2012), o processo de inclusão é determinado pela interação entre variáveis individuais e do contexto. Nenhum sujeito é incluído (ou excluído) só pelas suas capacidades individuais, nem só pelas características do contexto social ou educacional. O processo de inclusão é interativo, dinâmico e resulta da influência mútua de diferentes fatores. A característica dinâmica desse processo implica em desequilíbrios, novos equilíbrios, 
instituição de outros valores e atitudes em função das transformações ocasionadas pela inclusão. A relação do estudante com deficiência com a universidade é interativa e deve considerar as características específicas desses estudantes, suas necessidades de um lado e, de outro, os recursos e as possibilidades da universidade. $\mathrm{O}$ reconhecimento do direito à educação desses sujeitos precisa ser assegurado, assim como o direito à igualdade de oportunidades e à participação social.

Assim, o acesso das PCD ao ensino superior é o passo inicial do processo de inclusão. Conforme Cabral e Melo (2017) pode ser considerado como marco histórico desse processo a Declaração dos Direitos das Pessoas com Deficiência de 1975. Na esteira desta Declaração, principalmente a partir das décadas de 1980 e 1990, outros documentos nacionais e internacionais foram sendo elaborados, com vistas a garantir os direitos das PCD, mais precisamente no que se refere à inclusão educacional desses sujeitos nos diferentes níveis de ensino. Dentre os movimentos internacionais em prol da inclusão, os mais relevantes são: i) a Conferencia Mundial de Educação para Todos (1990); ii) a Conferência de Salamanca, que resultou na Declaração de Salamanca: sobre princípios, políticas e práticas na área das necessidades educativas especiais (1994) e iii) a Declaração Mundial sobre Educação Superior no Século XXI: visão e ação (1998).

No Brasil, os reflexos dos movimentos mundiais em prol da Educação Inclusiva incidiram diretamente em dois dos mais importantes documentos sobre essa matéria: a Política Nacional de Educação Especial na Perspectiva da Educação Inclusiva - PNEEPEI (2008) e a Convenção sobre os Direitos das Pessoas com Deficiência - Lei Brasileira de Inclusão (Lei 13.146/15). Ambos os documentos trazem em seu texto aspectos que se relacionam diretamente à garantia de acesso das $\mathrm{PCD}$ aos diferentes níveis de ensino.

A PNEEPEI (2008), dentre outras diretrizes, assegura que o acesso, a participação e a aprendizagem das pessoas com deficiência, transtornos globais de desenvolvimento, altas habilidades/superdotação devem ocorrer em todos os segmentos de ensino, sendo a Educação Especial transversal, desde a educação infantil até a educação superior. Assegura, ainda, a continuidade da escolarização das PCD nos níveis mais elevados do ensino. $\mathrm{O}$ reconhecimento jurídico e social das diferenças no âmbito das políticas de ações afirmativas direcionadas à promoção do acesso das PCD ao ensino superior no Brasil é um tema emergente em todo o território nacional. Tal discussão surge a partir de movimentos de luta pelos direitos das PCD e outros grupos historicamente marginalizados.

No Brasil, algumas instituições de ensino superior, antes mesmo da Lei 12.711/12, adotavam políticas de ações afirmativas de ingresso destinadas a candidatos de escolas 
públicas, pretos e pardos, indígenas e ou PCD. A universidade do Estado do Rio de Janeiro (UERJ), em 2002, foi a primeira instituição a garantir o sistema de vagas no seu vestibular (CABRAL, 2018). Foi em 28 de dezembro de 2016, com a promulgação da Lei 13.409/2016, que a reserva de vagas para esse público nas instituições de ensino superior e nos cursos técnicos de nível médio foi efetivada

Com a expansão do ensino superior em nosso país, a flexibilização dos processos seletivos e as políticas afirmativas (cotas e reserva de vagas), tanto nas universidades públicas quanto nas privadas, o público do ensino superior está cada vez mais diverso. Tais iniciativas tem significado, em alguns casos, a entrada de alunos que sem tais ações certamente não chegariam às universidades.

Entre uma das políticas públicas instituídas em favor da inclusão no ensino superior podemos citar o Programa Incluir. Este programa teve início em 2005 e voltava-se para o fomento de ações que visavam o pleno acesso das pessoas com deficiência na universidade. Uma das principais ações do Programa Incluir foi o fomento à criação de núcleos de acessibilidade no âmbito das instituições federais de ensino superior. Tais núcleos se constituem de diferentes maneiras. Não há um direcionamento comum na elaboração das ações de inclusão, resultando no fato de que cada universidade construiu o seu processo de trabalho.

A construção de estratégias para possibilitar a permanência dos alunos com deficiência na universidade está entre os trabalhos realizados pelos núcleos de acessibilidade. Dentre o público atendido pelos núcleos estão as PCD e demais estudantes que, por motivos de ordem psicológica, dificuldades de relacionamento, esquizofrenia, depressão e outros transtornos demanda um atendimento especializado.

A despeito desta política pública, muito se precisa avançar em relação a possibilitar a permanência dos estudantes com deficiência. Em um estudo realizado por Anache et al., (2014) são indicadas algumas ações que podem contribuir para a construção de culturas e práticas inclusivas na universidade. As autoras chamam atenção para a sensibilização da comunidade universitária; pesquisas sobre as concepções que a comunidade acadêmica tem acerca da inclusão; desenvolvimento de atividades de ensino, pesquisa e extensão que contemplem as PCD; criação de estágios supervisionados; criação de instrumentos capazes de identificar e avaliar os estudantes que precisam de um atendimento e acompanhamento acadêmico que se aproximem das práticas de atendimento educacional especializado; orientação do corpo docente e de funcionários de diferentes setores da instituição; realização 
de um diagnóstico sobre as condições de acessibilidade da instituição. Esses são alguns aspectos que favorecem a permanência dos estudantes com deficiência na universidade.

Importa ressaltar que por se tratar de um processo interativo entre as PCD e os contextos universitários, cada instituição deve avaliar a sua realidade e, a partir dela, construir possibilidades de tornar o seu cotidiano mais inclusivo e acessível a todos.

Pelo exposto, fica claro o quão complexa é a discussão acerca da inclusão de PCD no ensino superior. Diante de tantos desafios que se colocam para as universidades, o trabalho docente é, certamente, um dos mais fundamentais. Sobre essa questão passaremos a discorrer na seção que se segue.

\section{A docência no ensino superior: das relações entre formação, atuação e inclusão educacional}

As reflexões que se seguem partem da compreensão de que ser docente no ensino superior não é apenas uma questão de domínio de conteúdo, de expertise em determinado campo do conhecimento ou de titulação acadêmica. A docência no ensino superior exige práticas pedagógicas sintonizadas com o conjunto de atividades próprias ao trabalho do professor numa instituição de ensino superior: ensinar, pesquisar, promover extensão acadêmica, inovação e cultura.

A educação superior no Brasil está expressa nos artigos 43 a 57 da Lei de Diretrizes e Bases (LDB, Brasil, 1996). Conforme a LDB, as instituições que ofertam a educação superior têm por finalidade a formação profissional nas diferentes áreas do saber, promovendo a divulgação de conhecimentos culturais, científicos e técnicos, comunicando-os por meio do ensino. Cabe ainda ao ensino superior: o estímulo à criação cultural e o desenvolvimento do espírito científico e do pensamento reflexivo, promovendo o trabalho de pesquisa e a investigação científica e o fomento à extensão; a divulgação ampliada para a população sobre a criação cultural e a pesquisa científica e tecnológica geradas nas instituições que oferecem a formação em nível superior e produzem conhecimento.

A formação do docente para o ensino superior e a constituição de uma pedagogia universitária compõem um campo de estudos e investigações de diferentes pesquisadores brasileiros. Segundo Pimenta e Anastasiou (2008), embora os professores universitários possuam experiências significativas na área de atuação, ou tenham um grande embasamento teórico, predominam, em geral, o despreparo e até um desconhecimento científico do que seja um processo de ensino e de aprendizagem. As razões para essas constatações são diversas. De 
acordo com as reflexões de Masetto (1998, p. 36), até a década de 1970, "praticamente exigiase do candidato a professor de ensino superior o bacharelado e o exercício competente de sua profiss o", com base no princípio de "quem sabe, sabe ensinar". Acreditava-se que para o exercício da docência no ensino superior fosse suficiente o domínio de conhecimento específico - pesquisa ou exercício profissional no campo. Soares e Cunha (2010) reforçam essa reflexão quando chamam a atenção para a ausência de exigência nas políticas públicas de uma formação ampliada para o professor da educação superior que contemple os saberes específicos da prática docente, além dos já mencionados conhecimentos científicos específicos das áreas do saber. Referenciando a diversos estudos, as autoras expõem que o professor do ensino superior constrói sua identidade docente a partir das vivências familiares, dos modelos de antigos professores e da própria experiência autodidata, além das trocas com colegas de profissão e do retorno dos estudantes.

No atual momento histórico os novos objetos técnicos trazem com eles novos signos. Testemunhamos a multinacionalização das empresas, a internacionalização da produção e do produto, a mundialização da economia, os novos papéis do Estado e a revolução da informação que, com o progresso da informática, passa a conectar instantaneamente as pessoas e os lugares (AMORIM, 2010, p. 68). O mundo de hoje é marcado por este sempre novo "meio-técnico-científico-informacional", cujos maiores elementos explicativos denominam-se conhecimento, cultura e técnica. "Hoje, gra as aos progressos técnicos e à mundialização da economia, a existência, ainda que incompleta de uma comunidade humana universal, permite reconhecer, em cada acontecer, uma fagulha do mundo" (SANTOS, 2005, p. 162). A produção do conhecimento e a formação em ensino superior ocupam lugar de destaque no debate das novas demandas formativas advindas desses contextos, trazendo como elemento fundamental o exercício da docência frente aos desafios de ensinar e aprender no mundo contemporâneo.

Libaneo (2012) nos ensina que entre o trabalho dos professores e a atividade de aprendizagem dos estudantes intervêm os fatores do contexto que atuam nas condições pedagógicas-didáticas do trabalho docente. Para o autor,

[...] o trabalho docente consiste numa atividade mediadora entre o individual e o social, entre o aluno e a cultura social e historicamente acumulada [...] mas, trata-se de um aluno enquanto ser concreto e histórico, síntese de múltiplas determinações, produto de condições sociais e culturais (LIBANEO, 2012, p. 341). 
Em tempos de mudanças muito significativas no âmbito das técnicas e suas variações de uso e da produção, acúmulo e transmissão acelerada do conhecimento e informação é imperioso pensar em mudanças nas práticas docentes do ensino superior. Uma série de novas tecnologias são acessadas pela população, principalmente pela juventude que acessa os cursos superiores. O domínio de um conjunto de novas maneiras de produção e exibição da escrita, da imagem e dos sons traz consigo, igualmente, novas maneiras para ensinar e aprender. Desafios postos às instituições de ensino superior e seu corpo docente que deve formar-se, continuamente, para atender a tais demandas formativas.

Não deslocados desse processo acelerado de transformações, constatam-se avanços no âmbito da política de inclusão de pessoas com deficiência (PCD) no mundo do trabalho e nos ambientes escolares. Como já mencionado, a Lei 13.409/2016, ao regulamentar a reserva de vagas para PCD em Instituições de ensino superior federais, traz consigo outros desafios ao ambiente universitário, seja em processos e dinâmicas da gestão acadêmica, seja no âmbito específico das práticas docentes em cursos superiores.

Enquanto na escola básica há duas décadas observa-se a promoção da formação docente para um trabalho pedagógico inclusivo, nas IES pouco se discutia a presença das PCD nos seus cursos superiores. Dessa forma, o desenvolvimento de uma cultura de inclusão no ambiente universitário é fundamental para trazer o debate da docência em ensino superior a partir de práticas inclusivas. O tema da inclusão nas IES precisa ser colocado em pauta e os pleitos das PCD e suas especificidades de acessibilidade e aprendizagens devem permear as discussões acadêmicas que compõem os projetos pedagógicos dos cursos.

A inclusão de PCD no ensino superior também esbarra em barreiras do campo atitudinal. Docentes, estudantes, servidores do quadro técnico, entre outros sujeitos que circulam no ambiente universitário, ignoram, desconhecem ou conhecem muito pouco, de maneira geral, as limitações e as capacidades de aprendizagem de estudantes com deficiência. O desconhecimento é portador do preconceito que permeia discursos que contribuem com a exclusão, o desânimo, a retenção e abandono dos cursos (OMOTE, 2004, 2005).

Atualmente, o que se observa é uma corrida nas IES para organização de quadros que deem conta de promover, minimamente, processos inclusivos desde a seleção dos candidatos, em programas de ingressos mais equânimes, até a organização didática das disciplinas nos cursos. Nesse âmbito, é crucial fomentar programas de formação docente e de corpo técnico para o trabalho com PCD. A formação do docente para o ensino superior no Brasil acontece nos cursos de pós-graduação e não contemplam, minimamente, as metodologias e didáticas para o trabalho no ensino superior. Tal formação passa longe da discussão sobre quem são os 
sujeitos da aprendizagem; em quais contextos socioeducativos as práticas docentes serão realizadas; quais aprendizagens os currículos devem promover, entre outras.

Nossa pesquisa na base de dados da Scielo reportou um número muito pequeno de artigos publicados em língua portuguesa que reflita sobre o trabalho docente e inclusão no ensino superior, dado que apresentaremos da seção seguinte. Essa ausência demonstra a carência de pesquisas na área da formação de professores e das práticas docentes no ensino superior em face do processo de inclusão de PCD em IES públicas federais brasileiras. Tal processo inclusivo acontece num contexto conturbado de escasseamento do financiamento do ensino superior público no Brasil e a política de inclusão de PCD, nessas instituições, não tem garantido amento próprio, para além do já citado "Programa Incluir", que $\quad \square$ atende a todas as demandas advindas da entrada de PCD nas IES a partir da política de reserva de vagas.

Um dos grandes desafios colocados a partir da política de reserva de vagas para PCD é o de garantir o ingresso e a permanência dos estudantes no curso escolhido. Os primeiros movimentos das IES precisam convergir para a compreensão de que o processo de inclusão no ensino superior deve atingir todos os indivíduos e criar condições sociais e pedagógicas de ensino para todos os estudantes. Para isso é necessário compreendê-lo enquanto processo social complexo, produto de ações estabelecidas por agentes distintos envolvidos diretamente ou indiretamente com o processo de ensino-aprendizagem, desde aqueles presentes no espaço acadêmico, como também presentes em seu entorno, tais como, professores, coordenadores de curso, diretores de unidades, técnicos administrativos, pais, membros da gestão universitária, entre outros.

A presença de grupos de pesquisas e estudos que já se debruçam sobre a temática da inclusão criam possibilidades para ampliar o debate nas IES e fomentar a cultura inclusiva por meio de seminários, rodas de conversas, cursos de formação continuada, entre outros. Ademais, a existência um ambiente de pesquisa e inovação nas instituições pode favorecer o desenvolvimento de uma série de soluções frente aos desafios para promoção da inclusão encontrados por professores, técnicos administrativos, gestores e os próprios estudantes. Diferentes interações entre as práticas docentes no ensino, na pesquisa e na extensão podem ser fomentadas e colaborar com o processo inclusivo no ensino superior.

Uma discussão também inserida no rol de demandas a serem cuidadas pelas IES e que impacta as práticas docentes está relacionada ao conjunto de normatizações que rege toda a ambiência acadêmica das instituições. A ampliação do número das PCD nos cursos de graduação das instituições federais de ensino superior tem mobilizado as discussões sobre os 
tempos, a permanência, a avalição, os currículos de formação em graduação para esse público, para citar algumas pautas já identificadas no interior das universidades.

Além de mobilizar os docentes em suas práticas, trazendo novas demandas no campo do ensinar e aprender, a presença das PCD nas IES federais tem instigado o campo da gestão acadêmica a buscar estratégias de formação continuada de docentes e servidores. Novos desafios para a oferta de uma graduação de qualidade são colocados, dadas as especificidades formativas das PCD em diferentes cursos. Infraestruturas adequadas à acessibilidade física e pedagógica são urgentes nesse movimento. A novidade dessa realidade e a escassez de reflexão constatada sinaliza para a existência de um campo vasto e aberto para atuação nas IES e seus docentes, grupos de pesquisa, cursos de pós-graduação e gestão.

\section{Metodologia}

Considerando o objetivo proposto, a saber: fazer uma reflexão sobre o quanto o acesso de estudantes com deficiência no ensino superior, em especial a partir da política de reserva de vagas (Lei 13.409/2016), tem impactado no cotidiano das salas de aula, em particular nas práticas docentes, esta pesquisa foi realizada a partir de uma revisão de literatura, sustentada pela metodologia de pesquisa bibliográfica narrativa (BOTELHO, 2011). Tal metodologia nos permite traçar uma análise sobre o conhecimento já produzido sobre a temática, que, no caso deste estudo, se refere à docência no ensino superior frente à inclusão de PCD.

Conduzimos a pesquisa tendo como fonte ambientes virtuais de acesso público, mais especificamente a base de dados do Scielo (Scientific Electronic Library Online), entre 2008 e 2018. Para a busca dos artigos empregamos os seguintes descritores: docência no ensino superior, docência universitária, inclusão de pessoas com deficiência, instituições de ensino superior.

Como critérios de inclusão estabelecemos: artigos completos, disponibilizados em português; publicados entre 2008 e 2018, inclusive; ter como foco a relação entre a docência no ensino superior e a inclusão de PCD. Os critérios de exclusão foram: artigos indisponíveis ou com problemas de exibição; publicados em outros idiomas; que não tratem da temática central da pesquisa. No total foram encontrados, num período de 10 anos, apenas 07 (sete) artigos que relacionavam diretamente a questão da docência no ensino superior com a inclusão de PCD. 


\section{Resultados e discussão: afinal o que as pesquisas nos revelam?}

Após a leitura de todo o material foi possível categorizar os artigos a partir dos seguintes subtemas: 1) formação dos professores; 2) desafios didático-metodológicos; 3) atitudes sociais frente à deficiência; 4) acessibilidade. Por entendermos que os subtemas se inter-relacionam e estão, juntos, no processo de inclusão de PCD nas Universidades, optamos por organizar os dados de forma discursiva, de modo que fique clara a inter-relação entre eles.

Os 07 (sete) artigos encontrados nos possibilitaram correlacionar diferentes elementos que perpassam pelo exercício da docência no ensino superior. Apesar da constatação da escassez de estudos que focalizem a docência universitária e a inclusão de estudantes com deficiência, os artigos que tivemos acesso trazem indícios de que a chegada de PCD nas universidades tem promovido um movimento de "desequilíbrio", no que tange à cultura universitária e às práticas docentes. Um primeiro indício que as pesquisas apontam é a constatação de que a formação de professores universitários carece de uma abordagem pedagógica, em particular, os saberes necessários para atuar com estudantes que apresentam deficiências ou outras necessidades educativas especiais.

É o que nos informa o artigo de Messerschmidit e Castro (2016). Ao realizarem um estudo com professores de uma universidade federal do Rio Grande do Sul, traçaram um perfil dos professores quanto ao ensino de alunos com deficiência. O questionário aplicado aos professores indicou que a formação inicial e continuada dos mesmos não possibilitou que os docentes tivessem acesso a saberes que os instrumentalizassem a trabalhar com PCD.

Em outro artigo, ainda no que se refere à formação, Malusá, Santos e Portes (2010), ao realizar um estudo com docentes da Universidade Federal de Uberlândia, ouviram dos participantes que a formação acadêmica é importante para que o professor adquira saberes necessários à prática com PCD, entretanto, a importância da experiência foi colocada numa posição de destaque pelos docentes. Ou seja, ter um estudante com deficiência em sala de aula, conviver com esse estudante e viver essa experiência impacta fortemente sobre a prática docente.

Santos e Duarte (2017), ao abordarem a temática do desenvolvimento profissional dos professores universitários numa perspectiva inclusiva chamam atenção para o fato das universidades e instituições de ensino superior realizarem maior investimento na formação dos professores. Defendem que essas instituições tenham programas de desenvolvimento profissional e que tais programas possam abordar questões que tocam à inclusão de PCD no ensino superior. 
Sobre a formação continuada dos docentes universitários os diferentes estudos apontaram para o fato de que as inciativas ou programas de formação são isolados e muito pontuais, havendo necessidade de as universidades desenvolverem ações e serviços de apoio que congreguem iniciativas de formação e pesquisas já existentes. As demandas dos doentes em relação à formação incluem: palestras, cursos, capacitação, orientações, flexibilização curricular e apoio aos estudantes. (PROVIN; FABRIS, 2015; SILVA, CYNNOT; D`ANTINO, 2012).

$\mathrm{Na}$ interface com a formação estão as questões didático-metodológicas. Essa é uma temática central quando pensamos na permanência dos estudantes com deficiência nas universidades. No estudo de Messerschmidit e Castro (2016), a fragilidade na mediação pedagógica foi um dado relevante. Dos professores que participaram do estudo, uma parte declarou não mudar a sua metodologia de ensino diante do fato de ter alunos com deficiência em sala de aula. As principais estratégias metodológicas relatadas pelos docentes foram: trabalho em grupo, aula expositiva e recursos visuais. Uma minoria dos professores relatou promover mudanças para adaptar suas aulas às necessidades específicas dos estudantes com deficiência.

Importa destacar, como demonstraram Malusá, Santos e Portes (2010), que as concepções difusas que os docentes têm a respeito da deficiência influencia significativamente na maneira como se posicionam diante desses alunos no cotidiano da universidade. Tais concepções passam por visões assistencialistas, de menos valia, incapacidade, até visões que consideram que deficiência não é sinônimo de incapacidade e que, apesar das dificuldades, as PCD são capazes de aprender e exercer uma profissão. Os docentes não desconsideram que as dificuldades são muito grandes, dependendo das limitações que a deficiência acarreta, mas não acreditam que tais limitações impedem completamente esses sujeitos de estarem na universidade.

Retomando o aspecto didático metodológico, Pieczkowski e Naujorks (2015), em seu estudo, buscam tencionar o processo de inclusão de PCD no ensino superior e compreender os seus efeitos na docência universitária. As autoras entrevistaram professores de duas universidades de Santa Catarina, na região Sul do país. A partir das narrativas dos docentes foi possível perceber que alguns relataram ter modificado e melhorado a sua prática em função de terem estudantes com deficiência nos seus cursos. Passaram a ter mais atenção a aspectos como expressão corporal, leitura labial, estímulos visuais, diversificação das propostas de atividade e avaliação. Na contramão desta postura, alguns docentes demonstraram não realizar qualquer mudança na sua prática, se opondo duramente ao 
processo de inclusão. Em uma das entrevistas é possível perceber que existe um processo de responsabilização do estudante pelo seu sucesso ou fracasso, como se apenas ele tivesse que se esforçar e superar as dificuldades para acompanhar as aulas.

Candido, Nascimento e Martins (2016), em seu artigo, destacam a centralidade do professor no processo de inclusão. Sem desconsiderar que tal processo prescinde de ações que extrapolam o trabalho docente, nos informam que a relação professor-aluno é uma questão determinante. Para os autores o professor precisa atuar como um mediador da aprendizagem e ter um compromisso ético com a sua função.

A temática da acessibilidade arquitetônica e de materiais diversos esteve presente em todos os artigos encontrados. De forma mais detalhada, Silva, Cynnot e D’antino (2012), estabeleceram, a partir da pesquisa com docentes universitários, o que os mesmos consideram, numa ordem de prioridade, essencial para possibilitar a permanência dos estudantes com deficiência na universidade. No topo das prioridades os docentes apontam a acessibilidade física, seguida da acessibilidade no mobiliário. A acessibilidade e adaptação de materiais e recursos aprece em terceiro lugar. Tal dado nos leva a refletir que não basta que os professores estabeleçam uma outra metodologia de trabalho se a instituição como um todo não se mobilizar para promover mudanças, para além da sala de aula, que promovam a inclusão de PCD.

A acessibilidade ao currículo também aparece em diferentes estudos. Diversificação e flexibilização curricular, formas diversificadas de avaliação, adaptações em ambientes como laboratórios de ensino e apoio aos estudantes mediante monitoria foram questões consideradas fundamentais pelos docentes universitários. No artigo de Pieczkowski e Naujorks (2015), fica evidente a preocupação de alguns docentes em relação a prover acessibilidade pedagógica aos estudantes com deficiência. Uma das questões que os docentes se preocupam é com o fato de não nivelarem por baixo o seu grau de exigência nas atividades e avaliações em razão dos estudantes terem algum tipo de limitação. Para os professores é importante diversificar as metodologias e manter o nível de exigência que é estabelecido para a turma.

Pelo exposto, percebemos que a complexidade envolvida no processo de inclusão de PCD no ensino superior é grande, em especial no que toca à atuação do docente. Os artigos nos sinalizam diferentes desafios à prática docente que vão desde a sua postura diante de estudantes com deficiência até a sua capacidade de ressignificar e modificar a sua prática tendo a inclusão como um princípio pedagógico. O cenário está posto, e cabe a todos que 
atuamos no ensino superior, seja como docentes, seja como gestores, construirmos uma cultura universitária coerente com os princípios da inclusão educacional e da diversidade.

\section{Considerações finais}

Esse artigo buscou refletir sobre o quanto o acesso de estudantes com deficiência no ensino superior, em especial a partir da política de reserva de vagas (Lei 13.409/2016), tem impactado no cotidiano das salas de aula, em particular nas práticas docentes. Motivados pela urgência do tratamento da temática em ambiente acadêmico, a lei de reserva de vagas no ensino superior para PCD impõe uma necessária reflexão sobre inclusão no ensino superior para docentes, quadros técnicos, gestores, estudantes e toda sociedade.

Algumas universidades já trazem um repertório de experiências nesse campo, mas o que se observa e constata pelos artigos acessados é que a maioria das instituições e seus quadros de servidores estão despreparados para o trabalho pedagógico de qualidade com o público de estudantes com deficiência.

De maneira geral, o que a leitura dos artigos elencados aponta é uma necessária mudança na formação inicial de docentes para o exercício do magistério em cursos de graduação. Política essa proposta e regulada pela Coordenação de Aperfeiçoamento de Pessoal de Nível Superior (CAPES) e que pouco tem trazido essa demanda para o debate na pós-graduação. Essa constatação é complementada pelo apontamento feito nos textos de ausência ou de escassez de uma política institucional de formação continuada de docentes, com atenção especial para os desafios e possibilidades da inclusão no ensino superior.

$\mathrm{O}$ atual cenário sociopolítico e econômico em que a inclusão de PCD no ensino superior ganha a cena e se apresenta com importante discussão sobre a garantia de direitos tem sido marcado pelo contingenciamento de recursos no campo educacional, o que agrava o já comprometido orçamento destinado às politicas inclusivas nas IES. Tal fato amplia, ainda mais, os desafios que temos que enfrentar, daqui para adiante, para consolidar o direito à educação das PCD e construir uma universidade cada vez mais diversa, inclusiva e que responda às necessidades acadêmicas e pedagógicas de seus estudantes.

\section{REFERÊNCIAS}

AMORIM, C. C. O uso do território brasileiro e as instituições de ensino superior. 2010. 335 f. Tese (Doutorado em Geografia Humana) - Universidade de São Paulo, São Paulo, 2010. 
ANACHE; A. A.; ROVETTO, S. S. M.; OLIVEIRA, R. A. Desafios da implantação do atendimento educacional especializado no Ensino Superior. Revista Educação Especial, v. 27, n. 49, p. 299-312, 2014.

BOTELHO, L. L. R.; CUNHA, C. C. A.; MACEDO, M. O método da revisão integrativa nos estudos organizacionais. Gestão e Sociedade, v. 5, n. 11, p. 121-136, 2011.

BRASIL. Lei n. 9.394/96, de 20 de dezembro de 1996. Lei de diretrizes e bases da educação nacional. Diário Oficial da União, Brasília, 23 dez. 1996.

BRASIL. Secretaria de Educação Especial. Política nacional de educação especial na perspectiva da educação inclusiva. Brasília: MEC, 2008.

BRASIL. Lei n. 13.146, de 6 de julho de 2015. Institui a lei brasileira de inclusão da pessoa com deficiência. Estatuto da Pessoa com Deficiência. Diário Oficial da União, Brasília, 7 jul. 2015.

CABRAL, L. S. A.; MELO, F. R. L. V. Entre a normatização e a legitimação do acesso, participação e formação do público-alvo da educação especial em instituições de ensino superior brasileiras. Educar em Revista, Curitiba, v. 33, n. esp., p. 55-70, dez. 2017.

CANDIDO, E. A. P.; NASCIMENTO, C. R. S. do; MARTINS, M. de F. A. Acessibilidade na educação superior também envolve o trabalho pedagógico. RIAEE - Revista IberoAmericana de Estudos em Educação, v. 11, n. esp. 2, p.1017-1033, 2016.

DEMO, P. Educar pela pesquisa. 2. ed. Campinas: Autores Associados, 1997.

LIBÂNEO, J. C. Ensinar a aprender, aprender a ensinar: o lugar da teoria e da prática em didática. In: LIBÂNEO, J. C.; ALVES, N. Temas da Pedagogia. Diálogos entre didática e currículo. São Paulo: Cortez, 2012.

MALUSÁ, S.; SANTOS, A. F.; PORTES, R. M. de L. Docência universitária numa perspectiva inclusiva: concepções e práticas no Ensino Superior. Revista Linhas. v. 11. n. 2. p. 145-168, jul./dez. 2010.

MASETTO, M. T. Professor universitário: um profissional da educação na atividade docente. In: MASETTO, M. T. (Org.). Docência universitária. 10. ed. Campinas: Papirus, 2009. p. 926.

MESSERCHIMIDT, D. E.; CASTRO, S. F. Docência com alunos com deficiência na universidade. Journal of Research in Special Educational Needs, v. 16, n. 1, p. 394-398, 2016

PIECZKOWSKI, T. M. Z.; NAUJORKS, M. I. Olhares docentes sobre a inclusão de estudantes com deficiência na educação superior. Revista Cadernos de Educação, n. 52. 2015 .

PIMENTA, S. G.; ANASTASIOU, L. das G. C. Docência no ensino superior. São Paulo: Cortez, 2008. 
PROVIN, P.; FABRIS, E. T. Os desafios da docência na universidade para todos: ações ou atitudes de inclusão? Revista do Centro de Educação, v. 40, n. 2, p. 319-331, maio/ago. 2015.

RODRIGUES, D. A inclusão na Universidade: limites e possibilidades de construção de uma Universidade inclusiva. Revista Educação Especial, Santa Maria, n. 23, p. 1-5, 2012. Disponível em: https://periodicos.ufsm.br/educacaoespecial/article/view/4951. Acesso em: jun. 2019.

RODRIGUES, D. Inclusão e Educação: doze olhares sobre educação inclusiva. São Paulo: Summus, 2006.

SANTOS, M. A Natureza do espaço. Técnica e tempo, razão e emoção. São Paulo: Edusp, 2005.

SANTOS, N. S.; DUARTE, A. C. S. Desenvolvimento profissional na educação superior: docência para uma educação inclusiva. Revista Educação, Cultura e Sociedade, Sinop/MT/Brasil, v. 7, n. 2, p. 338-349, jul./dez. 2017.

SILVA, A. M.; C. R.; D`ANTINO; M. E. F. Demandas de docentes do ensino superior para a formação de alunos com deficiência. Revista Brasileira Estudos Pedagógicos, Brasília, v. 93, n. 235, p. 667-697, set./dez. 2012.

SOARES, S. R.; CUNHA, M. I. da. Programas de pós-graduação em educação: lugar de formação da docência universitária? Revista Brasileira de Pós-Graduação, Brasília, v. 7, n. 14, p. 577-604, dez. 2010.

OMOTE, S. A constru o de uma escala de atitudes sociais em rela o à inclus o: notas preliminares. Revista Brasileira de Educa o Especial, Marília, v. 11, n. 1, p. 33-47, 2005.

\section{Como referenciar este artigo}

ANTUNES, V. C. K.; AMORIM, C. C. Os desafios da docência no ensino superior frente a inclusão de pessoas com deficiência nas universidades. Revista Ibero-Americana de Estudos em Educação, Araraquara, v. 15, n. esp. 2, p. 1465-1481, ago. 2020. e-ISSN: 19825587. DOI: https://doi.org/10.21723/riaee.v15iesp2.13800

Submetido em: 30/08/2019

Revisões requeridas: $30 / 11 / 2019$

Aprovado em: 02/02/2020

Publicado em: 01/08/2020 